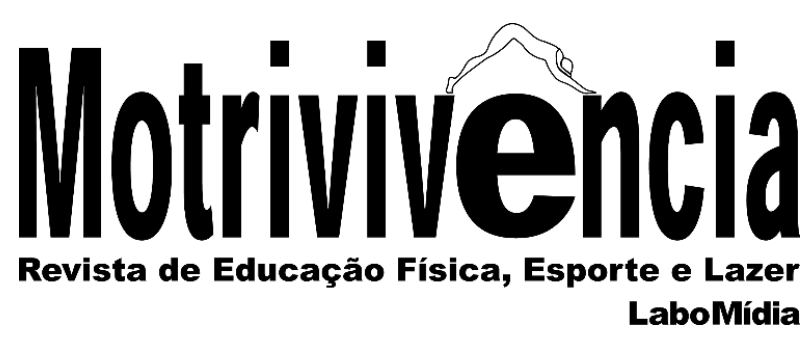

\title{
O karatê-do como instrumento de formação do caráter e personalidade dos praticantes através de suas técnicas corporais
}

\section{RESUMO}

Esta pesquisa objetiva investigar, com instrutores de Karatê-Do, a compreensão sobre relação entre técnicas corporais desenvolvidas nesta arte marcial e a formação do caráter do praticante, relação que segundo os autores da área é direta e incontornável. Como instrumento de coleta de dados, utilizou-se entrevistas com todos os instrutores atuantes desta arte marcial na cidade de Santarém-PA. Como resultado, vemos por exemplo $38 \%$ dos professores demonstraram trabalhar a formação do caráter e personalidade de forma direta e objetiva, sem considerar que as próprias técnicas são instrumentos de formação deste caráter, outros $54 \%$ puderam fazer tal raciocínio, enquanto $8 \%$ dos entrevistados demonstraram faze-lo assim, somente com as crianças, chegando-se a conclusão de que os instrutores, mesmo que não em sua totalidade trabalham as técnicas corporais como instrumentos de formação do caráter e personalidade e dão consciência a seus alunos disto.

PALAVRAS-CHAVE: Karatê-do; Corpo; Técnicas corporais

\section{Lucas Maciel Cavalcante}

Especialista em Docência na Educação Superior Centro Universitário da Amazônia - UNAMA

Santarém, Pará, Brasil. lucasmacielkarate@gamil.com D https://orcid.org/0000-0002-6178-5097

Petrônio Lauro Teixeira Potiguar Junior Mestre em Agriculturas Amazônicas Universidade do Estado do Pará-UEPA/DFCS Belém, Pará, Brasil ppotiguar@yahoo.com.br (D) https://orcid.org/0000-0001-9792-4266 


\title{
Karate-do as an instrument for training the character and personality of practitioners through their body techniques.
}

\begin{abstract}
This research aims to investigate, with Karate-Do instructors, the understanding about the relationship between corporal techniques developed in this martial art and the formation of the character of the practitioner, a relation that according to the authors of the area is direct and unavoidable. As an instrument of data collection, interviews were used with all instructors active in this martial art in the city of Santarém-PA. As a result, for example, 38\% of professors demonstrated that they were directly and objectively trained in character and personality, without considering that the techniques themselves are instruments of formation of this character, another $54 \%$ could make such a reasoning, while $8 \%$ of respondents have shown that they do so only with the children, and it is concluded that teachers, even if not in their totality, work with body techniques as instruments for the formation of character and personality and make their students aware of it.
\end{abstract}

KEYWORDS: Karatê-do; Body; Body techniques

\section{Karatê-do como un instrumento para entrenar el carácter y la personalidad de los practicantes a través de sus técnicas corporales.}

\section{RESUMEN}

Esta investigación objetiva investigar, con instructores de Karate-Do, la comprensión sobre relación entre técnicas corporales desarrolladas en este arte marcial y la formación del carácter del practicante, relación que según los autores del área es directa e ineludible. Como instrumento de recolección de datos, se utilizaron entrevistas con todos los instructores actuantes de este arte marcial en la ciudad de Santarém-PA. Como resultado, vemos por ejemplo el $38 \%$ de los profesores han demostrado trabajar la formación del carácter y personalidad de forma directa y objetiva, sin considerar que las propias técnicas son instrumentos de formación de este carácter, otro 54\% pudieron hacer tal raciocinio, mientras que el $8 \%$ de los entrevistados se ha demostrado que lo hacen así, sólo con los niños, llegando a la conclusión de que los instructores, aunque no en su totalidad, trabajan las técnicas corporales como instrumentos de formación del carácter y personalidad y dan conciencia a sus alumnos de esto.

PALABRAS-CLAVE: Karatê-do; Cuerpo; Técnicas corporales 


\section{INTRODUÇÃO}

Essa pesquisa se volta à relação das técnicas e protocolos do Karatê-Do com o processo de formação do indivíduo sobre o caráter e personalidade.

Esses pontos nos levam ao entendimento das técnicas corporais, partindo do trabalho clássico da antropologia de Marcel Mauss (2003), denominado “As Técnicas do Corpo”, que expõe a íntima relação entre o que o corpo expressa e os fatores históricos, sociais, políticos, econômicos e culturais, nos quais o indivíduo se encontra. Aspectos intimamente relacionados ao Karatê-Do, que revela em seus movimentos muito de sua carga histórico-filosófica (KANAZAWA, 2010).

Pensando nesta natureza e historicidade do Karatê-Do, destaca-se que por ser uma arte marcial japonesa, traz consigo protocolos e técnicas pensadas para um padrão comportamental e postural oriental, ressaltando-se que a ideia oriental de corpo, mente e espirito, é unitária, diferente da visão ocidental, que os separam (RIELLY, 2011; LE BRETON 2011).

Considerando tais fatores, a pesquisa objetiva, de forma geral, investigar entre os professores de Karatê-Do, a compreensão dos mesmos sobre a relação entre as técnicas corporais desenvolvidas nas aulas dessa arte marcial e a formação do caráter dos praticantes.

Neste sentido, demonstra-se a relevância do debate no pensamento de que essas correntes orientais vêm ganhando cada vez mais espaço no cotidiano ocidental, especialmente considerando o corpo em destaque, já que as atividades tipicamente orientais mostradas pelo autor, nesse movimento de aproximação, são propriamente físicas. Como exemplos lembra-se da Yoga, do Tai Chi e das correntes de medicina oriental, que se globalizam cada vez mais, graças as várias mídias e tecnologias envolvidas. Tal difusão deve motivar não só procura e curiosidade, mas também estudos na área (LE BRETON, 2011). O interesse científico pelo tema, especialmente por parte dos cursos de formação em Educação Física, é salutar e produtivo.

$\mathrm{Na}$ intenção de concretizar este estudo, realizaram-se entrevistas com todos os professores atuantes na cidade de Santarém-PA, seguindo esta problemática, na área específica, não só de autores clássicos como Mauss (2003), que defende que as técnicas do corpo expressam a constituição cultural do indivíduo, mas de outros que nos trazem a "invenção" e "re-significação" do corpo, ressaltando um processo constituído historicamente, e que hoje aproxima múltiplas vertentes, como as linhas orientais e ocidentais de pensamento (ALBUQUERQUE, 2001; GONÇALVES, 2007).

Esse processo de formação do caráter pessoal, e aprendizado, é tratado como necessariamente consciente (SAVIANI, 1993), e isso se torna ainda mais relevante nas artes 
marciais, já que a sua prática exige consciência individual, coletiva, social, histórica e filosófica (SOUSA, 2009).

\section{PERFIL METODOLÓGICO DA PESQUISA}

Essa pesquisa caracterizou-se como essencialmente qualitativa, se ocupando de problemas mais particulares relacionando com as Ciências Sociais, trabalhando com os símbolos, motivações, significados, vontades, dogmas e posturas, considerando, mais que o agir, a própria interpretação humana das ações e da realidade, em um nível que não pode ou não deveria ser quantificado (MINAYO, 2010), percebendo-se na análise de dados alguns aspectos quantitativos, para melhor visualização dos dados obtidos, com o uso de porcentagens para tanto.

Desse modo, entendemos ser a interdisciplinaridade, o caminho que mais se adequa a essa análise, rompendo fronteiras do que seja somente qualitativo e quantitativo, mas sim que a dialogicidade entre áreas (neste caso a educação física e a sócio antropologia) enriquece a produção do conhecimento dentro da academia.

Considerando os objetivos almejados pode-se enquadrar este estudo, como exploratório, pois busca aprofundar o conhecimento sobre o tema da construção do corpo no Karatê-do, partindo dos elementos bibliográficos estudados, indo à pesquisa de campo e a análise do material obtido (GIL, 2002; MINAYO, 2010).

Este trabalho se mostra dentro do explanado pelos autores de forma mais próxima a uma abordagem critico-dialética, por sua tendência a ação prática, graças a sua aplicação ao cotidiano pesquisado, vendo o indivíduo como fruto de sua produção e cultura, portanto sujeito ativo da constituição social (GIL, 2002; MINAYO, 2010), nesse caso, por meio e a partir de suas técnicas corporais, imbuídos da formação de caráter.

Para o desenvolvimento desta pesquisa de campo, os entrevistados eram maiores de idade, atuantes em espaços de promoção da arte marcial em seus moldes tradicionais, o que foi avaliado pela devida filiação desses professores a uma entidade consolidada de Karatê-do.

Ao todo foram entrevistados 13 professores, tanto na zona urbana, quanto rural da cidade de Santarém-PA, onde as entrevistas foram desenvolvidas com base em um roteiro de 8 perguntas norteadoras, desenvolvidas e aplicadas com o cuidado de não influenciar as respostas e cumprir com os objetivos da pesquisa (DUARTE, 2004). 
As questões tratavam das técnicas corporais do Karatê-do, sua historicidade e processo de formação crítico filosófica, ou seja, buscando saber de que forma elas são ou não, repassadas aos alunos.

Outro dado importante de análise, é o fato de a cidade pesquisada (Santarém, no estado do Pará), ser uma cidade interiorana, onde o Karatê-Do se encontra em expansão, sendo até o momento da pesquisa, relativamente pequeno o número de instrutores desta arte marcial, cujo tempo de formação, até a qualificação para ministrar aulas, gira em torno de 8 anos (KANAZAWA, 2010).

Os entrevistados eram todos do sexo masculino, com idades entre 18 e 52 anos, suas realidades de atuação com o ensino do Karatê-Do eram as mais diversas, sendo prioritariamente em projetos sociais, escolas e academias especializadas.

Para análise do conteúdo obtido nas entrevistas, as mesmas foram transcritas de forma integral, em seguida o conteúdo comum entre as falas foi agrupado em unidades de significação, passando então a seleção das unidades que mais interessavam ao cumprimento dos objetivos da pesquisa, sendo que o conteúdo em alguns momentos será exposto por meio de trechos da fala dos entrevistados, em itálico, para diferenciação das falas dos autores presentes nas referências bibliográficas (DUARTE, 2004; BARDIN, 1995).

Desta forma espera-se que ao final do trabalho, com o material obtido por meio das entrevistas, somado ao material bibliográfico, alcançar os objetivos do mesmo em suas conclusões, buscando seguir todas as indicações da lei 466/12, sendo esta produção devidamente aprovada pelo CEP sob o CAAE: 53765816.1.0000.5168.

\section{O KARATÊ-DO E AS TÉCNICAS DO CORPO}

Abordamos as concepções do indivíduo sobre o corpo e a construção de tais referências na realidade atual, que se caracterizam como "a invenção do corpo moderno e contemporâneo", ou seja, um processo paulatino, histórico e socialmente localizado, que perpassa por noções e reflexos particulares e coletivos (ALBUQUERQUE, 2001).

Neste sentido, a "A Re-significação do Corpo pela Educação Física Escolar, Face ao Estereótipo Construído na Contemporaneidade", acrescenta a ideia de que várias são as perspectivas corporais, havendo fortes influências das técnicas corporais sistematizadas nessas representações, especialmente quando estas se mostram como o novo, frente aos estereótipos ocidentais urbanos (GONÇALVES, 2007), a exemplo do Karatê-Do e outras tendências orientais. 
Vimos, ainda, que na formação sociocultural, relacionada ao corpo em destaque, em obras que "bebem" na fonte de Marcell Mauss (2003), é reforçada a atenção sobre as múltiplas influências orientais sobre perspectiva de corpo moderno e contemporâneo, assim como a impossibilidade de pensar o corpo dissociado dos fatores socioantropológicos nos quais está imerso. Como também é inviável pensar sociedade e cultura sem considerar a corporeidade individual e coletiva, pensamentos que potencializam práticas como o Karatê-Do, Yoga, e a própria medicina chinesa, enquanto instrumentos de formação pessoal e transformação social (LE BRETON, 2010, 2011)

Isso nos leva ao pensamento sobre corporeidade de que “... o movimento, neste sentido, passa a ser refletido numa visão que considera o inteligível/mente e o sensível/corpo como dimensões indissociáveis constituintes da unidade do ser humano.” (JOÃO; BRITO, 2004, p.263).

Nesta influência múltipla entre corpo e sociedade, o ponto chave no desenvolvimento deste tema se encontra no debate das técnicas corporais (MAUSS, 2003). A ideia é que as expressões corporais são marcas da personalidade, cultura e realidade social de um indivíduo, o que nos remete também as influências de códigos de conduta postural, como os presentes no Karatê-Do, que, numa via de mão dupla, também atuam na personalidade, cultura e realidade social de seu praticante (KANAZAWA, 2010).

Esta aproximação se dá também por razões históricas, e aqui associadas com concepção corporal e arte marcial, onde nota-se o pensamento de que para uma luta ser considerada uma arte marcial, deve relacionar-se, ao menos em sua historicidade, com a guerra, já que o termo marcial remete ao Deus Marte, o Deus da Guerra para os romanos. Por isso mesmo conta com um arcabouço de técnicas e tradições de combate, que carregam consigo uma filosofia, uma história (GAIO, 1996), como é o caso do Karatê-Do, que se inspira nas práticas dos tradicionais guerreiros Samurais japoneses (KANAZAWA, 2010).

Em sua obra "As técnicas do Corpo", Mauss (2003) avalia, em exemplos, posturas de militares. Diante delas identifica a origem geográfica dos indivíduos observados, o que além de ser uma constatação de sua ideia, nos traz mais uma relação direta de concordância com a origem do Karatê-Do em sua marcialidade e corporeidade, que "apresenta-se como proposta para a superação da visão mecanicista fragmentadora do princípio da unidade do ser humano.” (JOÃO; BRITO, 2004, p.263). A relação entre tais pontos se dá de forma contextualizada, apropriando-se de uma base clássica da antropologia para o debate da corporeidade e do Karatê-Do em si.

Destaca-se, ainda, que outra grande influência para o Karatê-do está nos ensinamentos passados com grande embasamento no Zen Budismo que, por vezes, se apoiam muito mais no aprendizado interior da prática constante dos exercícios do que no discurso filosófico do mestre, ou 
seja, o "Karateca" aprende a filosofia marcial por meio dos protocolos e técnicas corporais, e não pela fala de seu professor (RIELLY, 2011; MAUSS, 2003).

Ressalta-se também como a significação dessas práticas corporais vêm se perdendo ao longo da ampla difusão do Karatê-Do pelo mundo, defendendo que os mestres, professores e instrutores não podem também se perder do cerne da formação pessoal através da técnica e dos protocolos, mesmo que tenham de fazer adaptações metodológicas para ensinar aos diversos públicos (NAKAYAMA, 1996).

Aprofundando o debate, cabe acrescentar definições diretas ao pensamento de Rielly e Nakayama sobre os significados e objetivos das práticas corporais e protocolos presentes no KaratêDo.

Em se tratando de protocolos e formação do caráter, destaca-se que nas aulas é obrigatória a proclamação do Lema do Karatê-Do, denominado Dojo Kun, recitado por todos de forma solene, seguindo os padrões japoneses em seus protocolos posturais de máximo respeito e humildade.

O Dojo Kun é composto por cinco metas afirmativas que devem ser buscadas: "Esforçar-se para a formação do caráter! Fidelidade para com o verdadeiro caminho da razão! Criar o intuito do esforço! Respeito acima de tudo! Conter o espírito de agressão!” Trata-se de um protocolo que reafirma a unidade entre corpo e mente (LE BRETON, 2011) e a importância da técnica corporal para a formação integral do indivíduo (MAUSS, 2003), somado a uma filosofia de vida onde o respeito e a ética são bases fundamentais.

A execução da fala do Lema Dojo Kun deve ser feita após um momento de meditação com ênfase no processo respiratório, onde se aconselha utilizar apenas a respiração diafragmática e concentrar-se no baixo abdômen (KANAZAWA 2010).

Em se tratando do baixo abdômen e quadris, esta região é considerada o centro de gravidade e força do ser humano (KANAZAWA, 1987, 2010; NAKAYAMA, 1996). Em japonês este centro energético chama-se Hara, que na filosofia oriental é relacionado ao equilíbrio entre corpo, mente e espirito, favorecendo a capacidade de controle emocional do indivíduo. Tal visão coaduna perfeitamente com o pensamento de construção cultural relacionada às técnicas corporais (MAUSS, 2003).

De fato, na realidade oriental não se concebe dicotomia entre corpo e mente, sendo ambos tratados como duas faces de uma mesma essência, que se equilibra no baixo abdômen (Hara), sendo o fortalecimento desta região diretamente relacionado ao equilíbrio mental e espiritual. Em algumas sociedades japonesas a boa conduta social é relacionada a um "Hara forte" (KANAZAWA, 2010). 
Vê-se que a prática correta dos exercícios e protocolos fortalece corpo, mente e relações sociais. Neste sentido, se destaca também o forte costume de cumprimentar-se, presente no KaratêDo. Além do ato de curvar-se, se destaca a pronúncia alta e forte do Oss!, que longe de limitar-se ao cumprimento de uma regra hierárquica, é a expressão sincera de humildade e respeito. A expressão pode também servir como mantra motivador que ajuda a "suportar a pressão", sendo esta a tradução literal do termo (KANAZAWA, 1987).

O Oss! é utilizado como cumprimento universal, podendo substituir uma saudação de despedida, agradecimento, dentre outras. Porém, seu significado está relacionado ao exercício do esforço em suportar qualquer pressão ou empecilho que altere o equilíbrio interno do praticante de Karatê-Do (KANAZAWA, 1987). Tal cumprimento é feito geralmente junto com o ato de curvarse, próprio dos costumes tradicionais japoneses. Assim sendo, a corporeidade, o movimento corporal contextualizado e a comunicação não falada sustentam tal relação (JOÃO; BRITO, 2004; MAUSS 2003).

Vê-se que todas as práticas realizadas no Karatê-Do carregam significação profunda. Dentre as que relacionam-se ao golpes propriamente ditos, a mais antiga e de maior destaque é o Kata. Trata-se de uma luta imaginária contra vários oponentes, que traz consigo as marcas de seus mestres criadores, dos momentos históricos de criação e do desenvolvimento global do ser humano. A prática do Kata fortalece as base das ideias dos autores aqui já citados (KANAZAWA, 1987; MAUSS, 2003; LE BRETON 2010,2011).

Trazendo algumas considerações acerca do trabalho de tais técnicas corporais, tão enraizadas na cultura oriental, alerta-se sobre as necessárias adaptações do Karatê-Do a realidade atual globalizada, sem perder a essência da arte marcial (RIELLY, 2011; NAKAYAMA, 1996).

Com olhar pedagógico e acadêmico, aponta-se à cultura amazônica como força interferente na prática da arte marcial nesta região. A utilização, por exemplo, de figuras folclóricas para a melhor compreensão da filosofia do Karatê-Do é pedagogicamente salutar, pois a aproxima do imaginário cultural local (ÁVILA, 2005).

Portanto, as alterações nas práticas influenciadas pela realidade amazônica, são inevitáveis e devem ser assumidas, nos direcionando à relação cultura e corpo (MAUSS, 2003) e as articulações cultura e sociedade (LE BRETON, 2010) e a corporeidade (JOÃO; BRITO, 2004).

No mesmo caminho conceptual, defende-se que o conteúdo precisa criar raízes profundas no entendimento de quem o recebe, passando a ter significação para o mesmo. Assim tornando-se um componente da consciência filosófica do indivíduo e não somente mais uma informação do senso comum, o que deve acontecer também com as técnicas corporais próprias do Karatê-Do (SAVIANI, 1993). 
Tal pensamento sobre o ensino das lutas se une ao de que:

Os alunos devem entender o significado dos treinamentos dentro de um contexto físico e cultural, pois de certo modo contribui para o entendimento deles quanto as modificações fisiológicas e conhecimento sobre o corpo. Trata-se de muito mais que o aprendizado de movimentos de ataque e defesa, constitui-se no entendimento dessa manifestação cultural em todos os níveis e relações, a criação e desenvolvimento dos movimentos, historicamente produzidos, enquanto finalidade de combate ou autodefesa; os preceitos que norteiam as artes marciais orientais e a relação desses com o contexto social e cultural na época; a presença em filmes e desenhos animados, e a compreensão dos exageros e efeitos especiais; os eventos desportivos enquanto movimentos sociais, econômicos e políticos; as diferenças entre as modalidades; os benefícios e riscos psicológicos e físicos, da pratica de lutas (SOUSA,2009, p. 35).

Diante disso, fica clara a grande carga filosófico-cultural presente no Karatê-Do e a opinião dos autores da área sobre a desejada penetração destes ensinamentos no cenário contemporâneo de qualquer realidade geográfica, o que muito tem a contribuir no contexto da Educação Física, relacionando corpo, cultura e técnicas corporais e corporeidade.

\section{RESULTADOS E DISCUSSÃO}

Inicialmente deve-se esclarecer que são vários os caminhos para análises de resultados em pesquisa, e que há a plena certeza de que todos são válidos, mas aqui, devido à natureza ampla do trabalho, optou-se, para melhor compreensão da representatividade proporcional das opiniões coletadas, que serão apresentadas estatísticas diretas dos dados obtidos, através de porcentagens para melhor compreensão e visualização da representatividade das opiniões captadas.

Para enriquecer as análises, foram utilizadas falas dos sujeitos da pesquisa apresentadas em itálico para diferenciação dos autores de referência, como forma de materializar o conteúdo obtido e aproximá-lo ou não das reflexões teóricas trazidas pelos autores.

Quando questionados se o Karatê-Do é um instrumento de formação do caráter individual, os professores afirmaram que sim, porém 15\% defendem que "Não depende em si do Karatê, mas sim, como em toda arte marcial, de quem é o seu professor", ou seja, a positividade do caráter formado depende do bom exemplo e condução do professor, tal pensamento converge com o de Nakayama (1996) no sentido de que, não só a postura do professor, mas o próprio contexto de ensino, podem prejudicar o potencial formativo que é próprio do Karatê-Do.

Outros 85\% defendem algo como "A importância da formação no Karatê, é pra que eles (os alunos) entendam não só as técnicas, mas o conceito das técnicas e a filosofia do Karatê", 
resposta que se aproxima naturalmente o cerne central deste trabalho, no que diz respeito a forma como as técnicas corporais são abordadas por Mauss (2003), como forma de expressão cultural, chegando também ao pensamento da corporeidade presente em Comin e Amorim (2008), valorizando a expressão corporal como também formadora de cultura, numa via de mão dupla que fortalece indivíduo e arte.

Nas respostas ao primeiro questionamento, vemos uma maioria dos entrevistados valorizando o Karatê-Do como natural formador do caráter e personalidade, e a minoria discordante condicionou uma "boa formação do caráter" á influência direta do instrutor.

Solicitou-se na segunda pergunta que os entrevistados citassem que pontos deste caráter e personalidade que são atingidos ou formados pela prática do Karatê-Do (destacasse que a soma passa dos $100 \%$ já que cada professor citava mais de uma virtude).

A disciplina aparece em $46 \%$ das entrevistas, o respeito foi a segunda virtude mais citada (por 38\% dos professores), seguida da postura social, que foi debatida neste tópico por 30\% dos entrevistados, defendendo que o "Karateca" tem uma postura diferente onde chega, sabendo se portar em várias situações, pensamento presente também nos autores específicos do Karatê-Do, que aprofundam esse debate (KANAZAWA, 2010).

Ainda sobre a questão anterior, perseverança ou persistência foi citada por $23 \%$ dos entrevistados, enquanto a humildade foi citada em 15\%, seguidas por bondade, amor, companheirismo, concentração, tranquilidade e domínio de si, que foram citados por apenas $8 \%$ dos professores.

Essas falas servem para mostrar a amplitude de virtudes positivas relacionadas a prática do Karatê-Do, fortemente abordadas nos diversos autores da área, em uma perspectiva global e local (ÁVILA, 2004; KANAZAWA, 2010); NAKAYAMA, 1996; RIELLY, 2011; SOUSA, 2009), o que é de suma importância investigar, pois é salutar ao saber que a atividade auxilia na formação de um bom caráter, identificar ao certo quais virtudes são mais ou menos desenvolvidas.

$\mathrm{Na}$ terceira questão, que trata das metodologias de ensino, 38\% dos professores demonstraram trabalhar de forma oral e com recursos visuais os fundamentos de formação do caráter do praticante, de forma direta e objetiva, sem demonstrar que levam em conta que as próprias técnicas são instrumentos de formação deste caráter, conceito inerente aos costumes orientais, subjetivamente nelas localizados, como visto em Mauss, (2003), Rielly (2011) e Kanazawa (2010).

Essa realidade de ensinamentos presentes de maneira subjetiva nas próprias técnicas, se reforça nos filmes de artes marciais, onde se aprende a técnica e filosofia de maneira indireta e 
inconsciente, o que nos processos pedagógicos ocidentais atuais se vê de maneira consciente e objetiva (SOUSA, 2009)

Outros 54\% dos professores puderam fazer o raciocínio de relação entre as técnicas corporais e o desenvolvimento da personalidade do indivíduo, seja pela prática reflexiva dos protocolos de cumprimentar-se durante as aulas, ritos como o dojo kun, entre outras práticas também físicas, porém com inspiração filosófica.

$8 \%$ dos entrevistados demonstraram faze-lo da mesma forma somente com as crianças, e quando seu público fica adulto, já se passa a trabalhar de forma mais direta, o que nos leva a diferença de metodologia para as diferentes idades que foi citada pelos entrevistados, e nos autores específicos do Karatê-do, que nos remetem a adaptações ainda mais profundas como as necessárias a nossa realidade amazônica e educacional (SOUSA, (2009); ÁVILA, (2005))

A partir deste ponto da pesquisa se tem um foco menor na dinâmica das aulas e passa-se a valorizar o ponto central das técnicas corporais desenvolvidas no Karatê-do.

$\mathrm{Na}$ questão seguinte foram abordadas de forma direta as influências das técnicas corporais enquanto práticas propriamente físicas, não só nos ensinamentos do Karatê-do, mas na formação do caráter individual e personalidade dos praticantes.

Nesta análise podemos ver um cenário menos dividido, já que $15 \%$ dos entrevistados ainda permaneceram demonstrando uma visão apenas anatomofisiológica da aplicação das técnicas corporais e protocolos da arte marcial, o que segundo Le Breton (2011) é natural no contexto ocidental de fragmentação cartesiana do ser humano, e inclusive torna atividades de origem oriental um atrativo às sociedades ocidentais modernas, pois quebra com o padrão e abre novas possibilidades.

Enquanto todos os outros, $85 \%$, demonstraram uma relação direta ou indireta com a formação filosófica envolvida nas técnicas, como defendido na corporeidade, que mesmo sendo abordada em diversos trabalhos, sempre traz a relação "pessoa-ambiente, buscando visão mais integradora desses elementos" (COMIN \& AMORIM, 2008, p.1) como defendido também pelos autores específicos do Karatê-Do, a exemplo de Kanazawa (2010) que em sua obra discorre sobre por exemplo a importância de estar descalço nos treinos, para sentir e aproveitar melhor a energia que vêm do solo.

Passando então ao debate de algumas técnicas corporais específicas, tidas como fundamentais pelos autores do Karatê-Do, na quinta questão o questionamento aos entrevistados se voltou ao simples ato de se curvar durante as aulas, onde apenas $8 \%$ dos professores não citaram a palavra "respeito" em sua resposta, e mesmo estes, baseiam suas respostas na cultura tradicional 
japonesa, e na demonstração de valorização do outro (KANAZAWA, 1987), ou seja, mesmo sem usar a palavra "respeito", segue-se o padrão de pensamento tido pelos demais entrevistados.

Outra técnica corporal característica do Karatê-do é a utilização do termo "oss", na sexta pergunta questionou-se o significado e serventia do termo, demonstrando-se três níveis de compreensão: o primeiro que foi demonstrado por $15 \%$ dos entrevistados, é o do uso do termo oss enquanto um mantra que significa "suportar a pressão" e além disso utilizado como sinal de respeito, reverência e humildade entre os praticantes de Karatê em diversas situações cotidianas, sendo quase um cumprimento universal, pensamento que converge com o de Kanazawa (1987), sendo para o autor, a soma do ato de curvar-se com a pronúncia do termo oss, o gesto mais clássico e fundamental de respeito, na prática correta do Karatê-Do, perpassando o lema da arte, o Dojo Kun, onde pode se ver a frase "Respeito acima de tudo".

O que em se tratando de gestos com significações profundas, nos remete também a análise das técnicas corporais de Mauss, (2003) e da corporeidade de Comin e Amorim (2008), na intima relação entre o indivíduo e o ambiente, já que muitos dos praticantes de Karatê-do aderem a práticas como o uso do oss como medida natural de adaptação ao meio.

Essa visão exclusivamente prática, cotidiana, como um cumprimento universal foi demonstrada por $38 \%$ dos entrevistados, enquanto os outros $46 \%$ demonstravam ver para além da utilidade, um instrumento de expressão de respeito, humildade etc, sendo lembrado também que oss "é uma linguagem universal que quer dizer muita coisa, um bom dia, boa tarde, um "eu te respeito"'[...] e é universal, todas as artes marciais, principalmente as orientais, usam esse termo", que vem sendo desvalorizado e negligenciado segundo os entrevistados, assim como outras práticas tradicionais do Karatê-Do, pensamento visto também na obra de Nakayama, (1996), que associa muito da perda de aspectos tradicionais de respeito e humildade ao excessivo foco competitivo do que deveria ser arte marcial.

Esse raciocínio procedimental, voltado aos protocolos obrigatórios na aula, nos remete ao treino propriamente dito, e na sétima pergunta, destaca-se que uma das técnicas mais utilizadas para o treinamento do Karatê-Do é "Kata", onde 46\% dos entrevistados valorizaram as vertentes históricas e filosóficas do desta prática, defendendo por exemplo que "o Kata é a história de uma luta que aconteceu”, o que reforça o aspecto mítico e folclórico, como visto em Rielly (2011), que além de trata-lo como uma meditação em movimento, graças a influência do zen budismo, também destaca como as práticas realizadas pelos monges de Shaolin se tornavam mitos graças a propagação de boca em boca, do que se enxergava de relance.

Enquanto os outros 54\% se mostram mais focados no Kata como "uma sequência de golpes premeditada, para o aperfeiçoamento da técnica”, sem considerar as tantas abordagens filosóficas, 
históricas e formativas (KANAZAWA, 2010); NAKAYAMA, 1996; RIELLY, 2011), ponto que merece atenção, já que outras técnicas, como o oss e o ato de curvar-se, tiveram maior representatividade para além da prática física (MAUSS, 2003) no que pode ser visto nas ideias dos professores entrevistados.

$\mathrm{Na}$ última questão, quando questionados sobre os reflexos práticos na vida social dos ensinamentos presentes nas técnicas corporais do Karatê-do, manifestados no dia a dia dos alunos, $15 \%$ dos professores ainda se mostraram voltados à perspectiva físico prática, defendendo que: "Vai mais pela prática, que depois de praticar bastante, aquilo se torna automático, alguém dá aquele tapinha nas costas e você já defende”.

Os outros $85 \%$ entrevistados citaram uma ampla gama de reflexos sociais, desde o combate a violência, até melhores possibilidades de emprego aos praticantes de Karatê-do por serem pessoas que sabem se portar em qualquer ambiente como também defendido por autores do Karatê-do a exemplo de Kanazawa (2010) e Nakayama (1996).

\section{CONCLUSÃO}

A pesquisa, até aqui, possibilitou perceber que os professores de Karatê-Do que atuam na cidade de Santarém, veem esta arte marcial como um instrumento de formação do caráter individual e personalidade de seus praticantes. Para a maioria dos entrevistados este processo parece ser regido pelos ensinamentos e exemplos passados do professor para os alunos, porém as técnicas corporais, enquanto práticas propriamente físicas, são fatores coadjuvantes no processo.

Nas entrevistas, notou-se que alguns veem nas técnicas corporais suas significações mais subjetivas, filosóficas ou mesmo históricas o que nos remete a Mauss, (2003), porém poucos as citaram como o instrumento principal de influência comportamental dos alunos. Diante disso, espera-se e acredita-se que o questionamento sobre tais temas dirigidos aos professores os instigue a reflexões e estudos, movimento de busca por conhecimentos na área, movimento este, que também deve ocorrer no meio acadêmico, ao olhar para as artes marciais, correntes de pensamento oriental e o Karatê-Do.

Também poucos pesquisados demonstraram trabalhar as técnicas de forma puramente mecânica, e mesmo esses têm o Karatê-Do como caminho de vida e transformação, mesmo que não por sua natureza, mas em sua opinião, pelo exemplo dos próprios professores que encaminham os treinos e influenciam as vidas de seus alunos, pensamento que pode-se aplicar também a todas as áreas de atuação do professor de Educação Física, ensinando mais do que somente o prático, por 
meio das técnicas corporais significativas social e historicamente, bem como pela fala e exemplo de vida.

O mesmo raciocínio se aplica quando se visa a formação da concepção corporal prestada aos alunos de Karatê-do: a grande maioria dos professores entrevistados leva seus alunos a esta reflexão, por vezes de maneira consciente e aprofundada.

O processo de adaptação ambiental e aproximação da cultura oriental necessários, segundo os entrevistados, traz aos praticantes de Karatê-do, a oportunidade de melhorias pessoais em todos os sentidos: desde o sentimento de confiança até a humildade, desde o compromisso com as metas pessoais até a solidariedade com as necessidades alheias, desde o falar mais, até o calar-se. Esperase que este estudo seja mais um passo neste caminho.

Alguns lembraram também que nem todos são capazes de ensinar ou aprender tais fundamentos benéficos, porém nenhum dos entrevistados cita malefícios na prática desta ou quaisquer outras artes marciais, e vê-se a partir de tal valorização do corpo como instrumento de formação do caráter, que é defendida por esta pesquisa. Assim, a avaliação de tal realidade perpassa diretamente as técnicas corporais e comportamentos propriamente ditos, e em se tratando de Karatêdo cada técnica e protocolo possui ampla significação filosófica.

De acordo com os autores aqui trabalhados, vê-se que o foco central da arte do Karatê-do está na formação da personalidade do indivíduo, que ocorre por meio das técnicas corporais da arte marcial e culmina numa formação consciente de concepção de corpo individual, que é historicamente e filosoficamente contextualizada, como defende a corporeidade (COMIN; AMORIM, 2008) .

Tal significação filosófica além de ser o cerne central do Karatê-Do, como dito pelos autores e entrevistados, proporciona melhor aprendizado (SAVIANI, 1993), o que atribui relevância a esta pesquisa, não somente no sentido de metodologia pedagógica, mas também por trazer à tona temas como a significação e percepção do corpo, a filosofia aplicada ao corpo e tantos outros temas pertinentes à Educação Física.

Claramente tal estudo não se aprofunda em todos estes temas abordados, que possuem suma importância à área, porém espera-se que este seja um fio condutor para muitos outros debates em torno das artes marciais, do corpo, da corporeidade, da educação e das correntes de pensamento orientais, onde o corpo, e seus significados, são problemáticas que podem receber atenção acadêmica, numa forma de ver a Educação Física sob uma perspectiva interdisciplinar e não somente biomecânica. 


\section{REFERÊNCIAS}

ALBUQUERQUE, Leila Marrach Basto de. As Invenções do Corpo: Modernidade e Contramodernidade. MOTRIZ - Revista de Educação Física - UNESP, v. 7, n.1, p.33-52, 2001.

ÁVILA, Paulo. Karatê-do na Amazônia. Santarém: Instituto Cultural Boanerges Sena (ICBS), 2005.

BARBOSA, Alyne Patrícia da Silva; DUTRA, Andréa Katiane Bruch; BRASIL, Eliana Amoedo de Sousa. Normas Técnicas Para Trabalhos Acadêmicos. 4ª ed. Canoas: Editora da ULBRA, 2013.

BARDIN, Laurence. Análise de Conteúdo. Edições 70: Lisboa, 1995.

COMIN, Fabio Scorsolini; AMORIM, Katia de Souza. Corporeidade: uma revisão crítica da literatura científica. Psicologia em Revista. Belo Horizonte v.14 n.1 jun. 2008.

DUARTE, Rosália. Entrevista em pesquisas qualitativas. Educar, Editora UFPR, Curitiba, n. 24, p. 213-225, 2004.

FILLIOZAT, Jean. O intercâmbio entre a Índia e o Império Romano durante os primeiros séculos da éra cristã. Revista de história. São Paulo, v. 23, n. 47, p.1-31, 2016.

FUNAKOSHI, Gishin. Karatê-Do Kyohan: o texto do mestre; Tradução Wagner Bull. 1 ed. São Paulo: Cultrix, 2014.

GAIO, Roberta. Ginástica rítmica desportiva "popular": uma proposta educacional. São Paulo: Robe, 1996.

GIL, Antônio Carlos. Como elaborar projetos de pesquisa. 4. ed. - São Paulo: Atlas, 2002.

GONÇALVES, Andreia Santos; AZEVEDO Aldo Antonio de. A Re-significação do Corpo Pela Educação Física Escolar, Face ao Estereótipo Construído na Contemporaneidade. Pensar a Prática, v.10, n. 2, p.201-219, jul./dez 2007.

JOÃO, Renato Bastos; BRITO, Marcelo de. Pensando a corporeidade na prática pedagógica em educação física à luz do pensamento complexo. Revista Brasileira de Educação Física e Esporte. São Paulo, v.18, n.3, p.263-72, jul./set. 2004

KANAZAWA, Hirokazu. Faixa Preta: Karatê. São Paulo: Escala, 2010.

KANAZAWA, Hirokazu. S.K.I. Kumite Kyohan. Tokyo: Ikeda Shoten Co, 1987.

LE BRETON, David. Sociologia do Corpo/ Tradução de Sonia M.S. Fuhrmann. $4^{\text {a }}$ ed. Petrópolis, RJ: Editora Vozes, 2010.

LE BRETON, David. Antropologia do Corpo e Modernidade/ Tradução de Fábio dos Santos Creder. Petrópolis, RJ: Editora Vozes, 2011. 
MAUSS, Marcel. Sociologia e Antropologia. Tradução: Paulo Nevez. São Paulo: Cosac Naify, 2003.

MINAYO, Maria Cecília de Souza (org.). Pesquisa social: teoria, método e criatividade. 29. ed. Petrópolis, RJ: Vozes, 2010. (Coleção temas sociais)

NAKAYAMA, Masatoshi. O Melhor do Karatê: Visão abrangente-Práticas. São Paulo: Cultrix, 1996.

RIELLY, Robin L. Os segredos do Karatê Shotokan. São Paulo: Madras, 2011.

SAVIANI, Demerval. Educação: do Senso Comum a Consciência Filosófica. Campinas: Editora Autores Associados, 1993.

SHINZATO, Yoshihide. Shishukan Shorin Ryu Karate-do. Disponivel em: http://shinshukan.com.br/shorin. Acesso em: 22 de junho de 2015.

SOUSA, Smayk B. O ensino das lutas na escola. Belém: Gráfica Paraense Editora LTDA. 2009.

\section{NOTAS DE AUTOR}

AGRADECIMENTOS - Não se aplica.

CONTRIBUIÇÃO DE AUTORIA - Não se aplica.

FINANCIAMENTO - Recursos próprios.

CONSENTIMENTO DE USO DE IMAGEM - Não se aplica.

APROVAÇÃO DE COMITÊ DE ÉTICA EM PESQUISA

Aprovada pelo CEP sob o CAAE: 53765816.1.0000.5168.

\section{CONFLITO DE INTERESSES}

Não se aplica.

\section{LICENÇA DE USO}

Os autores cedem à Motrivivência - ISSN 2175-8042 os direitos exclusivos de primeira publicação, com o trabalho simultaneamente licenciado sob a Licença Creative Commons Attribution Non-Comercial ShareAlike (CC BY-NC SA) 4.0 International. Estra licença permite que terceiros remixem, adaptem e criem a partir do trabalho publicado, desde que para fins não comerciais, atribuindo o devido crédito de autoria e publicação inicial neste periódico desde que adotem a mesma licença, compartilhar igual. Os autores têm autorização para assumir contratos adicionais separadamente, para distribuição não exclusiva da versão do trabalho publicada neste periódico (ex.: publicar em repositório institucional, em site pessoal, publicar uma tradução, ou como capítulo de livro), com reconhecimento de autoria e publicação inicial neste periódico, desde que para fins não comerciais e compartilhar com a mesma licença.

\section{PUBLISHER}


Universidade Federal de Santa Catarina. Programa de Pós-Graduação em Educação Física. LaboMídia - Laboratório e Observatório da Mídia Esportiva. Publicado no Portal de Periódicos UFSC. As ideias expressadas neste artigo são de responsabilidade de seus autores, não representando, necessariamente, a opinião dos editores ou da universidade.

\section{EDITORES}

Mauricio Roberto da Silva, Giovani De Lorenzi Pires, Rogério Santos Pereira.

\section{HISTÓRICO}

Recebido em: 22 de outubro de 2018.

Aprovado em: 16 de abril de 2019. 